\title{
Moral Narration: An Effective Paradigm of Ideological and Moral Education in Contemporary Colleges and Universities
}

\author{
Tianfu Lin \\ School of Marxism, Minjiang University, Fuzhou 350108.China \\ 151667434@qq.com
}

Keywords: moral narrative, educational value, subjectivity, effectiveness, dialogue.

\begin{abstract}
Moral narration focuses on social and historical events, emphasizes the experience of real feelings and the practice of concrete life as well as transmit moral information, stimulate moral sentiment and expand the thinking world through narration in order to achieve the returning to humanism of moral education, which contains a profound solicitude for life and value reconstruction and is an effective paradigm to transfer socialist core values in colleges and universities.
\end{abstract}

\section{Introduction}

The moral dilemma of moral landslides and values alienation contributes to the great expectation of the contemporary world on the utility of moral education. Since 1980s, American moral education theory has changed its emphasis on cultivating moral reasoning and judgment ability to cultivate moral habits and emotions, they revisit the traditional moral education factors neglected by modern people, and trend to pay attention to virtue ethics, conservatism and the traditional moral education of communitarian. Aiming at the gradual warming of the study of value education, the "moral education" movement promotes the usage of moral narrative in the core value education, and which promotes the revival and development of American school moral values education. In China, moral narrative, as the main way of traditional moral education, which accompanied by the history of civilization for thousands of years. In the content, it carries the educational thought of Confucian ethical values, and in the form, it integrates into the strict education network of the traditional moral education. However, with the transformation of the concept of knowledge, moral narrative, the historical and new educational means seems to be forgotten by the domestic college moral educators. From the research and practice of moral narrative in modern western countries, moral narrative is the process of narrative subjects use the narrative of moral stories to discover or reveal the moral thoughts and values contained in these social and historical stories, and to promote the development of core values and good moral character of educated person.

\section{The Educational Value of Moral Narrative}

"Moral narration does not advocate the value neutrality, but advocates the core values of education, and it should combine with the mainstream value organically in the value of diverse reality. This is the western countries long-term review results and Reflection on their moral development, but also conforms to China's moral education experience." ${ }^{[1]}$ Generally speaking, the educational value of moral narrative is reflected in the following aspects:

(1)Moral narrative can improve students' subjectivity. The moral indoctrination method, formed in the process of moral education knowledge and theorization, which regards the students as the container of accepting knowledge passively, Ignores the individual experiences and feelings, the formation of the process of moral indoctrination method, the students as a passive acceptance of knowledge of the container, and this one-way instillation of abstract moral principles and norms resulting in the binary opposition between teachers and students, the subjectivity of the students is replaced by the overly emphasized subject position of the educator, and forming rigid and dogmatic model of moral indoctrination in practice, finally, result in moral education ineffective or even failure. This leads to the 
re-recognition and active adoption of the subjective moral education model in the process of educational practice. The subjective moral education model emphasizes that the object of education is the subject of moral education, advocates the two-way interaction between the subject of education and the subject and object of education, and it encourages that the education object actively participates and accepts .In the moral narrative, the interaction between teachers and students becomes the main body of the classroom, which breaks the closed and depressing state of the binary opposition between teachers and students, and also breaking the situation that teachers as a moral high point do moral preaching .By the "true story of moral awareness" to express the individual understanding and interpretation of the reality of moral life, through the role of interaction and exchange of both to achieve the goal that education object to proactively explore and actively accept something in the process of moral education, and it is initiative in moral learning and moral practice .

(2) Moral narrative makes education closer to life and improves the acceptability of teaching content. Moral knowledge is not obtained and confirmed by moral reasoning, but by people's moral life experience and recognition, that means it passed and generated through intimate feelings and telepathy ${ }^{[2]}$.Therefore, the most important is not logical reasoning, but understanding, sentiment and infection in the process of moral education. We should change the view of moral education from the intellectual logic to real social life, the moral education thought theory should contained in the vivid narrative, make the educated people return to the real life, and then reveal the true meaning and the intrinsic value of life. Tao Xingzhi said: "The fundamental meaning of education is the change of life. Life is not always the same, that is, life always contains the meaning of education", ${ }^{[3]}$ this suggests that moral education should be based on actual and vivid life, we should learn benevolence, justice, integrity and other values in daily life. In fact, moral narrative is to promote people to enhance their moral qualities and to cultivate their noble moral sentiments through the transmission of the causal theory of good and evil. The visual, comprehensive and vivid narrative from the life and higher than life, which can arouse listeners' sympathy and make them show their empathy. Moral narrative always entangle personal feelings and plot closely together in the process of narrative or deductive, this equal and open communication can promote students to deeply understand and dialectically explore the narrative themes based on the objective reality of social life, from which to understand the moral values and meaning contained in the story, and then make moral subtle into the individual's ideological consciousness.

(3) Moral narrative can stimulate students' moral emotion, and promote the formation of students' moral character. Moral narrative conforms to the psychological law of individual moral development. Kohlberg's moral development psychology holds that "the formation of human character is a process of unconscious and implicit habits." ${ }^{[4]}$ In the moral narrative, the narrative subject always incorporates some emotion, such as appreciation or approval or denial, which is the process of the internal unity of emotion and value judgment, and the value experience of the listener contributes to the empathy effect. All the moral forces are contained in the narrative of the story, through a strong emotional experience, sincere and active dialogue and the systematic guidance and summary, which makes both of listeners and narrators have emotional rendering and autonomous deconstruction, reconstruction and construction, and makes the moral education has a vivid, intuitive, rich, specific , understandable and specific examples of good and evil, and achieve the goal that the university students can feel morality, understand morality, reflect morality, discover morality, evaluate moral, choose moral and practice moral in a real sense, and then make them grasp the direction of progress, encouraging human nature to the good, make the moral story rose to moral awareness and change it into moral action, and lead to the high degree of the university students' knowledge, experience and action of moral, and finally promote the formation of good moral character of them. 


\section{The Mechanism of Moral Narrative in the Teaching of Ideological and Moral Education in Colleges and Universities}

In the course of moral education in colleges and universities, the course of "ideological and moral cultivation and legal basis" (hereinafter referred to as "basic") provides important guidance for college students' moral cognition system and moral education idea. However, in the process of educational practice, we teach too much systematic moral knowledge, and turn moral knowledge into human quality, and finally make teaching become indoctrination education to guide their own words and deeds. In this mode, students in a passive status to accept knowledge, educators ignore the practical experience of students in real life, through the vague sermon way to force students into a grand social and historical goals, leading to the formalism or dogmatism and even the vulgarism of the moral practice, and then triggering the emergence of the dual personality of individual students, finally resulting in moral education runs into a failure or invalid dilemma. In view of this, I believe that the most important thing in moral education is not to achieve the accumulation of moral knowledge with logical reasoning, but to promote the virtues development of the educated people with inspiration, understanding, concretion and moving. Therefore, vivid and rich moral narrative fit the educational requirements. The open and multi-solution moral narrative can make the listener and the speaker freely realize the construction of the self-emotion and the self-consciousness, and also can turn the moral education from the rigid stereotype logic to the vivid realism. Therefore, the moral narrative should be applied to the teaching process of "basic" course , and have a high degree fit between the moral story in daily life and moral emotion of educated people by the narrative of plural subject, and achieve seamless docking with the moral pattern in the mind of educated people ,then realize that the educated people consciously use the moral schema to re-analyze and recognize the story, in order to highlight the students' humanistic status in the "basic" educational activities .By using the moral narrative, to provide a more interpersonal, emotional, and imaginative paradigm for students to finally form the rational cognition of the relationship between individual morality and social whole morality, to generate an organic unity of the moral power of knowledge, emotion, ideas, beliefs and behavior, forming a specific moral experience, causing students to reconcile the moral emotions, and then enhancing the students' moral experience in the "basic" educational activities. Moral narrative gives students a certain degree of disposition and even the dominance, so that students have the opportunity to express and think about enriching the specific moral stories, to feel the inner world of others, and they are easier to accepted and recognized in emotional .In the process of moral narrative, educators are no longer preach various abstract principles and norms of moral knowledge, and students begin to bring the individualized understanding of morality into the classroom in the process of interaction. Moral narrative can create a good atmosphere, make the dialogue and thinking between teachers and students become rich, vivid, concrete and in-depth, and then make content of the "basic" educational activities become open from closed, the way of activities become excited from control, the abstract universal transform into a living individual. In the method, the instruction of teachers shifts to the equal dialogue between teachers and students, and then cultivate a good culture atmosphere of moral education. The moral narrative does not oblige students to summarize the moral heights that teachers demand to achieve from the story, but students understand the value of the story of the moral standards independently, thus consciously establish the socialist core values, and to achieve the goal that praise virtue and punish vice. This process fully respects the students' independent choice, increases the level of students' knowledge, broadens the students' horizons, enhances the students' ability to perceive the world and think independently, thus improving the students' comprehensive quality.

\section{The Practice of Moral Narrative in the Teaching of Ideological and Moral Education in Colleges and Universities}

In order to achieve the desired moral education effect in the course of moral education in Colleges and universities by using moral narrative, we must grasp the following aspects: 
First, the narrative theme should be effective, which is an important basis for the development of moral narrative.Teachers and students can choose the narrative theme for the teaching content and teaching objectives of the "basic" course. When choosing the narrative theme, we should pay attention to the moral image which must be close to the narrative object, so that both education and enlightenment are both important and effective to avoid the vulgarization of the subject matter selection; Vivid and interesting coexistence, both to deepen students' understanding of rational concepts, principles and perspectives, active classroom atmosphere, but also enable students to easily grasp the knowledge in the cheerful atmosphere, inspired and educated, to enhance the ideological and moral cultivation and Consciousness, to achieve a multiplier effect of teaching; Targeting with the times, to ensure the effectiveness of the narrative theme, by selecting the infectious and affluent themes, it is convenient for college students to realize the connotation of moral stories and internalize their own cognition according to their own moral life experience, and transform them into the moral thoughts of "true, good and beautiful" behavior.

Second, the narrative subject should choose the appropriate narrative way, so that through the emotional resonance to produce a true moral and emotional experience. Experience and practice show that the teaching effect of the "basic" course is highly correlated with the teacher's emotional input. The direct infection of teachers' teaching emotions has led to a positive emotional experience of students experiencing positive emotional experiences and active learning and learning, resulting in resonance and aroused enthusiasm for learning. In this process, the narrative subject is required to have strong moral awareness ability and ability to interpret the story text, so as to realize the definite meaning of narrative meaning can realize the effective interaction. Through the emotional expression of the narrative subject, the effective realization of the sharing and recognition of the values of both sides.

Third, the narrative subject should carry out the construction of the classroom atmosphere intentionally, and enhance the vivid and lively nature of the moral narrative. "Basic" class will be the mainstream ideology and the core values of socialism which contains, through the modular, three-dimensional knowledge structure of all-round training students to form the correct value orientation, a sound attitude towards life, it is not entirely pure sense of knowledge System, which inherently determines the "basic" teaching methods and methods of flexibility and diversity. To this end, the narrative subject through the introduction or creation of a specific vivid image as the main body of the situation, causing students a certain attitude experience, so that students in a specific situation in the atmosphere to obtain information, in-depth exploration, solve problems, summarize the law, personal knowledge and science The practical value of the method, the realization of creativity and potential to give full play to the completion of the concept of guidance to the practice of behavior transformation. The use of this method of classroom knowledge capacity, common participation is high, teaching atmosphere is good, learning interest thick, can effectively enhance the excitement of students and independent inquiry awareness, often can play a "ripple" effect. In this process, to ensure the diversity of the main narrative, teachers, students can alternately achieve the role of exchange, through the creation of the environment to achieve the resonance of both sides.

Fourth, the narrative subject should put forward a number of contextual problems and discuss the relevant knowledge points. In the teaching can be combined with the narrative theme will be representative, the typical problem placed in advance to the students, so that students have prepared, so as to improve the students' classroom attention and integration. Because students think about different aspects of the problem, there will be many new ideas and deep-seated problems, which will help students to independently analyze the problem, determine the problem and solve the problem. In this process, the narrative subject should pay attention to the attraction, representation, in-depth and enlightening nature of the problem itself, and fully explore the true emotion, attitude and values of the narrative object, through the discussion of the formation of knowledge aggregation, to reach a correct view, sublimation story, strengthen the theme.

Fifth, in the process of moral narrative teaching, teachers should be good at creating a democratic and equal atmosphere, to mobilize the autonomy of students, enthusiasm, in order to achieve a 
successful "dialogue." The process of realizing the goal of education requires teachers and students to complete the teacher and students together constitute the unity of educational activities, but in the traditional "basic" teaching process teachers in the center of power, and possession of age, knowledge, experience and other advantages, Its initiative and autonomy are often higher than the students, the teacher's subjective play too much, and the student initiative enthusiasm into the lack of, therefore, the narrative subject should be interested in the students in the "dialogue" in the process, to stimulate students to explore Enthusiasm, transfer teachers strong leadership of the classroom, from the educators into the students to explore the issue of the exchange of ideas, fully respect and absorb the rational composition of students' thinking, with a critical spirit to examine the existing authority of moral language to equality the value of the idea to explore the "shared values", recognize and respect the diversity of values, so that moral education return to the glory of human nature, so that students really become the main body of moral construction, to achieve teaching and learning. As the postmodern curator Dole says, "The role of the teacher is not abandoned, but is reconstructed, from the external student scene to the coexistence of the situation, and the authority is transferred to the scene."[5]"The teacher does not ask the student to accept the authority of the teacher; he asks the student to remain skeptical of the authority to encourage the student and the teacher to explore and explore what the student is experiencing. Teachers agree to help students, so that students can understand the meaning of their own advice, willing to face the students questioned, and students together to reflect each other to obtain the tacit understanding. " ${ }^{[6]}$ Teachers and students around the story to discuss, through the "dialogue" "discuss" the story behind the moral connotation, the interpretation of the meaning of the narrative meaning to the students, so that moral stories and meaning of sublimation for moral awareness, internalization of narrative object of moral literacy, eventually externalized into moral practice. At the same time, through the "dialogue" can also enhance students' innovative thinking ability and other ability to cultivate, such as eloquent eloquence, extraordinary courage, excellent adventure and pioneering spirit, positive team spirit.

\section{Conclusion}

In short, the moral narrative concerned about the daily life of the incident, emphasizing the real feelings of the experience and the practice of specific life, it is not abstract concepts or symbols to suppress the true experience of the education process, but through the narrative transmission of moral information, expand the world of thinking, in order to achieve the return of moral education, contains a profound life care and value reconstruction, effectively highlight its ideological and moral education in the effectiveness of the unique advantages. It is an effective way to avoid the ineffectiveness and invalidity of ideological and moral education in colleges and universities, and to promote the ideological and moral education of colleges and universities by making full use of moral narrative. It is not only the inheritance and development of the excellent moral education model in the East and the West, but also the new characteristics of the development of moral education model in the new period, is an effective paradigm for the transmission of socialist core values.

[This article is the Fujian Provincial Department of Education 2013 provincial and young teachers teaching project "The Influence of Contemporary Social Thoughts on College Students and the Countermeasures - Taking Fuzhou University as an Example"(Item No. JB13170S) Research Results]

\section{References}

[1]. Liu Xinling. Moral narrative and its reference [J]. Ideological and Political Education Research, 2006 (3): 55.

[2]. Wanjun people. The Story of Syria and Virtue - Reading "The Book of Beauty" [J]. Beijing: Reading, 2001 (6): 22-27

[3]. Dong Baoding. Tao Xingzhi's Educational Criticism [M]. Beijing: People's Education Press, 1991: 292-390. 
[4]. Kong Weimin. Implicit learning theory and school moral education [J]. Dalian: Educational Science, 2002 (3): 7.

[5]. Shao Qing Shi. Modern classroom management - building a balance between authority and freedom [J]. Journal of Heilongjiang Education Institute, 2009 (12): 44.

[6]. Doll, WE., Jr. A Post-Modern Perspective on Curriculum. Teachers College Press, 1993: 160

[7]. About the Author: Minjiang College School of Marxism, Lin Tianfu, male, born in November 1980, Quanzhou Nanan, graduate degree, lecturer, research direction: ideological and political education, economic sociology 